\title{
FLAME ATOMIC ABSORPTION SPECTROMETRY DETERMINATION OF SILVER NANOPARTICLES IN ENVIRONMENTAL WATERS USING DISPERSIVE LIQUID- LIQUID MICROEXTRACTION
}

\author{
WU, H. Z. ${ }^{1,2}-$ MENG, L. F. ${ }^{3 *}$ \\ ${ }^{I}$ Faculty of Land Resources and Engineering, Kunming University of Science and Technology \\ Kunming 650093, China \\ ${ }^{2}$ College of Mining Engineering, Guizhou University of Engineering Science \\ Bijie 551700, China \\ ${ }^{3}$ College of Chemical Engineering, Guizhou University of Engineering Science \\ Bijie 551700, China \\ *Corresponding author \\ e-mail:1025588702@qq.com
}

(Received 21 ${ }^{\text {st }}$ Jun 2018; accepted $22^{\text {nd }}$ Aug 2018)

\begin{abstract}
A novel, rapid low-density solvent based dispersive liquid-liquid microextraction has been developed for extraction and preconcentration of silver nanoparticles (AgNPs) prior to flame atomic absorption spectrometry analysis. In this study, water samples were first treated with acetonitrile/water $(80: 20, \mathrm{v} / \mathrm{v})$ which was then utilized as disperser solvent in the dispersive liquid-liquid microextraction process along with using 1-octanol as extractant. An enrichment factor of 57 is obtained, and the recoveries of AgNPs spiked into environmental samples are in the range of 96.7 to $108 \%$. A low limit of detection (LOD) of $6.5 \mu \mathrm{g} / \mathrm{L}$ is achieved using flame atomic absorption spectrometry (FAAS) for quantification. The relative standard deviation $(\mathrm{RSD})$ is $2.1 \%(\mathrm{n}=9)$. This proposed method provides an efficient approach for the analysis and tracking of AgNPs in the environmental water samples.
\end{abstract}

Keywords: AgNPs, DLLME, extractant, preconcentration, FAAS

\section{Introduction}

Metallic nanoparticles are of high importance in current materials research, with potential applications in biomedicine, energy conversion, imaging, or as pigments (Khaligh et al., 2015; Hartmann et al., 2013). Engineered nanomaterials (NMs) have already yielded a variety of commercially available products including cosmetics, antimicrobials, suntan lotions, paints, stain-resistant clothing and remediation products (Mirzaei et al., 2013). The rapid growth in the commercial use of AgNPs will inevitably increase silver exposure to the general population (Ghaedi et al., 2013). AgNPs may penetrate the skin (Ghaedi et al., 2015) via textile or wound dressing contact, be inhaled from some spray medicine, or ingress into the female genital tract by incorporation into female hygienic products or medical implants (Habila et al., 2015), and it is also toxic to human cells (Altunay et al., 2015; Fan et al., 2012; Choi et al., 2011). Therefore, it is important from an analytical point of view to develop sensitive and economical methods for determination of trace silver nanoparticles.

Because of the complexity of the matrices and trace amounts of metal ions residues in practical samples, sample preparation is necessary and often plays a vital role in the overall analytical scheme (Lambropoulou et al., 2007). In the past few years, a diversity of extraction methods, including liquid-liquid extraction (LLE) (Fernández-Gutiérrez et al., 1998), stir bar 
sorptive extraction (SBSE) (Van et al., 2007), solid-phase micro extraction (SPME) (Beltran et al., 2003) and solid-phase extraction (SPE) (Gil-García et al., 2006), have been developed for sample preparation. A wide range of applications hitherto bears testimony to the fact that they are portable and effective for sample preparation. However, for most of these methods, considerable time and organic solvent are needed for analytes to be extracted into the organic phase or onto the sorbent. In order to increase the throughput for sample pretreatment, the development of time saving and high efficient microextraction techniques has drawn much attention (Ding et al., 2013).

Dispersive liquid-liquid microextraction (DLLME) has been brought up as an exciting microextraction technique in 2006 (Yu et al., 2014; El-Shahawi et al., 2013; Rezaee et al., 2006). In this procedure, a mixture of high density organic solvent (serving as extraction solvent) and water miscible polar dispersive solvent (dispersive solvent) is rapidly injected into an aqueous sample to form an emulsion consisting of fine droplets of the extraction solvent, dispersive solvent, and water. Due to the extraction solvent being highly dispersed in the aqueous phase, the surface area between extraction solvent and sample solution is infinitely large, thus speeding up the extraction. While, the main disadvantage of DLLME is that the extraction solvent is generally limited to solvents with higher density than water in order to be sedimented by centrifugation, typically chlorinated solvents such as chlorobenzene, chloroform, and tetrachloromethane, all of them are potentially toxic to humans and the environment. To date, CPE has already successfully been applied for the quantification of Au-NPs in water samples in combination with electrothermal atomic absorption spectrometry (ET-ASS) (Hartmann et al., 2013). However, ET-AAS measurement, which background absorption signal is large, the relative sensitivity and sample in homogeneity more serious, analytical precision is poor.

In this study, the possibility of AgNPs enrichment by DLLME was considered. A new microextraction method combined with flame atomic absorption spectrometry (FAAS) was developed for separation, enrichment and determination of AgNPs in environmental waters. Factors affecting the extraction efficiency, such as $\mathrm{pH}$, concentration of extractant, extraction time, and nature of the extractant were studied and optimized.

\section{Materials and methods}

\section{Materials}

All chemicals used were analytical grade or better and all solutions were prepared in deionized water. 1-hexanol, 1-heptanol, 1-octanol, 1-nonanol, 1-decanol and decanoic acid were obtained from the Aladdin Reagent Corporation (Shanghai, China). Tannic acid, sodium carbonate, Ammonium sulfate, hydrochloric acid, silver nitrate, ethanol and sodium thiosulphate, all purchased from (Aladdin, China).

\section{Equipment}

A pHSJ-4A pH meter (Shanghai, China), vortex agitator (Shanghai, China) and SK5210LHC ultrasonic instrument (Shanghai, China), centrifuge (Shanghai, China) and flame atomic absorption spectrometer (AA6300, Shimadzu, Japan) were used.

\section{Synthesis of AgNPs nanoparticle}

Preparation of $\mathrm{AgNO}_{3}$ solution and tannic acid solution, $0.100 \mathrm{~mol} / \mathrm{L} \mathrm{Na} \mathrm{CO}_{3}$ solution with deionized water; amount of $200 \mathrm{~mL}$ tannic acid solution at three mouth bottle 
thermostatic water bath heating, and stirring; adding $5 \mathrm{~mL} \mathrm{Na}_{2} \mathrm{CO}_{3}$ solution to tannin reduction; after $10 \mathrm{~min}$, A certain amount of volume $\mathrm{AgNO}_{3}$ solution, with the constant pressure drop funnel the dropwise added to the above mixture. Three mouth bottle solution color from colorless to light yellow gradually, orange, red, and finally turned a deep red or red brown, continue stirring heating 30 min, obtained the AgNPs. The AgNPs concentration of the solution was determined by FAAS.

\section{Extraction procedure}

DLLME of AgNPs step

A $4 \mathrm{~mL}$ AgNPs sample solution placed in $10 \mathrm{~mL}$ long tapered glass centrifuge tube was adjusted to $\mathrm{pH} 3.0$ with diluted $\mathrm{HCl}$, and then $40 \mu \mathrm{L}$ of $1 \mathrm{M} \mathrm{Na}_{2} \mathrm{~S}_{2} \mathrm{O}_{3}$ and $80 \mu \mathrm{L}$ of 1 octanol (as extraction solvent of DLLME) were added to the acetonitrile/water (80:20, $\mathrm{v} / \mathrm{v}$ ) extract (used as disperser solvent) and the mixture was diluted to $40 \mathrm{~mL}$ by deionized water in a $50 \mathrm{~mL}$ vial with conical bottom. Then, the tube was sealed and swirled on a vortex agitator at $2000 \mathrm{rpm}$ for $30 \mathrm{~s}$ to accelerate the formation of the fine droplets of the extraction solvent and to enhance the transfer of the analytes. The supernatant aqueous phase can then easily be removed by decanting. The droplet was dissolved in $2 \mathrm{~mL}$ of ethanol and transferred to FAAS measurement.

\section{Results and discussion}

\section{Optimization of the DLLME conditions}

Parameters that commonly affect the DLLME efficiency, such as sample $\mathrm{pH}$, the type and volume of extraction solvent, salt content, equilibration time were investigated.

$\mathrm{pH}$ plays an important role on metal chelate formation and subsequent extraction. To optimize the extraction conditions for the nanoparticles $\mathrm{pH}$ was varied between 1 and 7 using hydrochloric acid for $\mathrm{pH}$ adjustment while the other experimental variables remained constant. The highest extraction efficiency was achieved at $\mathrm{pH} 3.0$ (Fig. 1) while the replicate times $\mathrm{n}=6$. So, $\mathrm{pH} 3.0$ was selected as the optimum for further experiments.

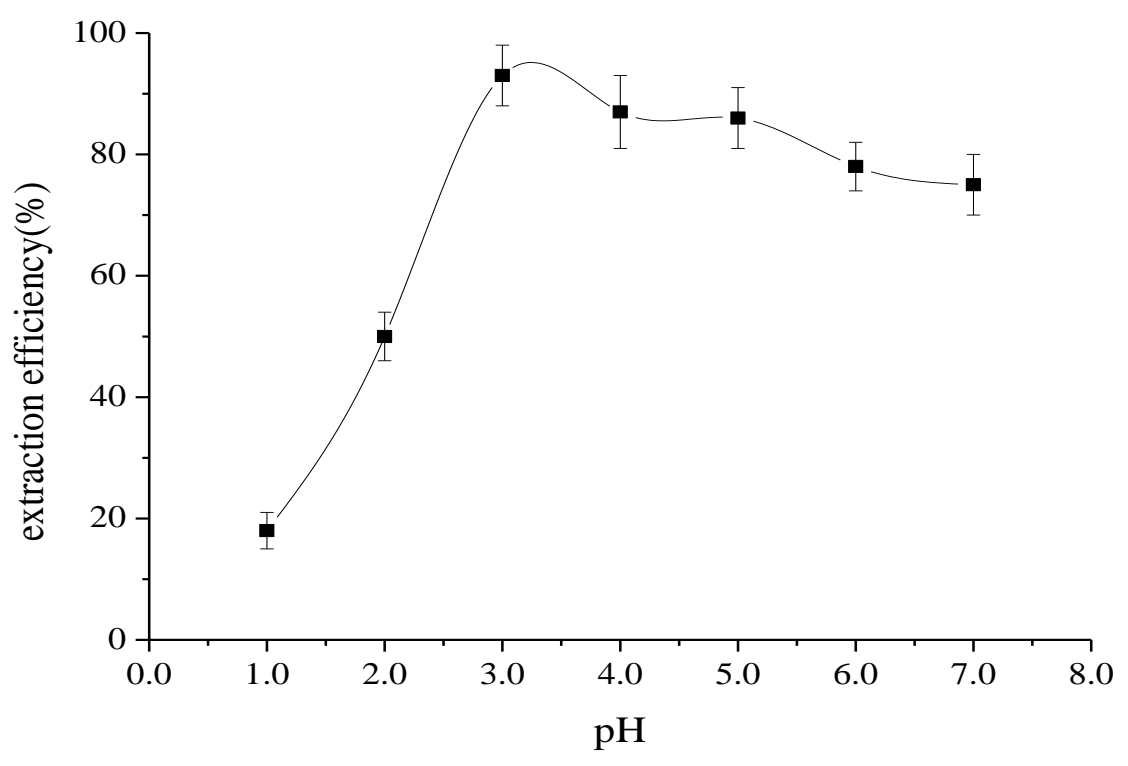

Figure 1. Effect of pH on DLLME of AgNPs 


\section{Selection of the disperser solvent}

The applicability of several organic solvents including $\mathrm{MeOH}, \mathrm{MeCN}, \mathrm{EtOH}, \mathrm{MeOH}$ $80 \%$ and $\mathrm{MeCN} 80 \%$ was investigated in the preliminary experiments taking into account that they should be used as primary extracts of the analytes from real water samples must then act as disperser solvent in DLLME process. Figure 2 shows the recoveries of the whole procedure of all extraction solvents tested. The results revealed that the maximum extraction efficiency was achieved by MeCN/water (80:20 v/v).

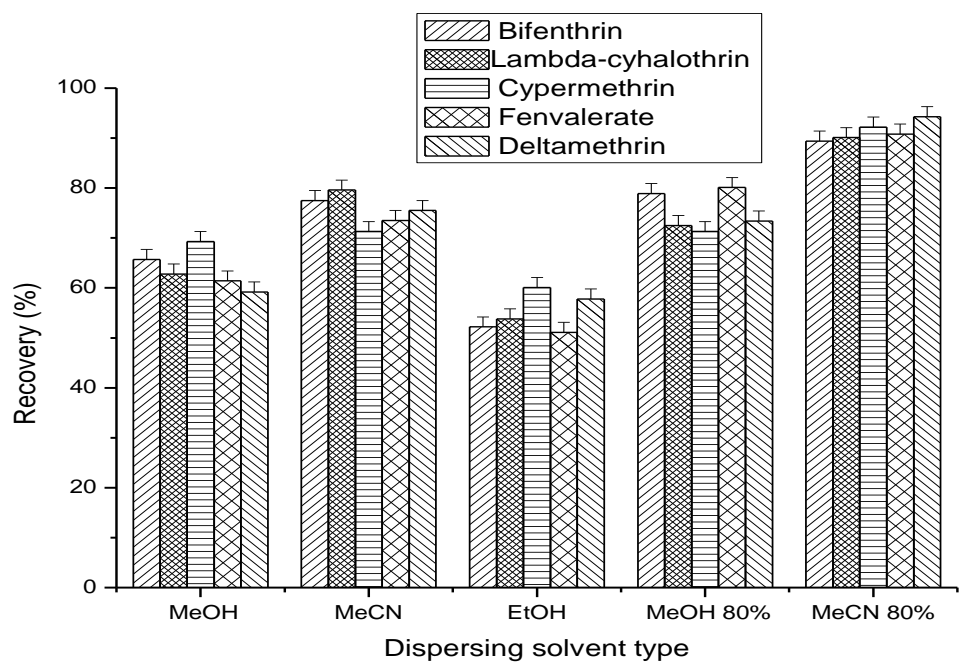

Figure 2. Effect of dispersing solvent

To study the volume effect of disperser solvent, it was varied from 4 to $12 \mathrm{~mL}$ in the interval of $2 \mathrm{~mL}$ while extraction solvent was kept at $80 \mu \mathrm{L}$. The obtained results showed that the extraction efficiency increased with increasing the volume of $\mathrm{MeCN}$ $80 \%$ up to $10 \mathrm{~mL}$ and then dropped down slightly above $10 \mathrm{~mL}$ due to the increased solubility of AgNPs in the aqueous phase and decreasing the distribution ratio.

Therefore $10 \mathrm{~mL} \mathrm{MeCN} \mathrm{80 \%} \mathrm{was} \mathrm{selected} \mathrm{as} \mathrm{both} \mathrm{the} \mathrm{extraction} \mathrm{solvent} \mathrm{of} \mathrm{AgNPs}$ from environmental samples and as disperser solvent in DLLME for subsequent experiments.

In this study $\mathrm{Na}_{2} \mathrm{~S}_{2} \mathrm{O}_{3}$ as a masking reagent to cover the interference of $\mathrm{Ag}^{+}$. When $\mathrm{Na}_{2} \mathrm{~S}_{2} \mathrm{O}_{3}$ was added, thiosulfate ions and silver ions generated thiosulfate (Fig. 3), which is soluble in water. Therefore, silver ions can be eliminated to the detection of AgNPs.

$\mathrm{Na}_{2} \mathrm{~S}_{2} \mathrm{O}_{3}+2 \mathrm{Ag}^{+}=2 \mathrm{Na}^{+}+\mathrm{Ag}_{2} \mathrm{~S}_{2} \mathrm{O}_{3} \downarrow$
$\mathrm{Ag}_{2} \mathrm{~S}_{2} \mathrm{O}_{3}+2 \mathrm{Na}_{2} \mathrm{~S}_{2} \mathrm{O}_{3}=\mathrm{Ag}_{2} \mathrm{Na}_{4}\left(\mathrm{~S}_{2} \mathrm{O}_{3}\right)_{3}$

Figure 3. The reaction of sodium thiosulfate with $\mathrm{Ag}^{+}$

\section{Selection of extraction solvent}

Selection of appropriate extraction solvent is of great importance in microextraction technique in order to obtain efficient extraction. For the LDS-DLLME, the extraction 
solvent should meet the following requirements: (1) be immiscible with aqueous solution (2) able to extract the analytes, and (3) possess low toxicity. To avoid the use of more highly toxic solvents such as trichloromethane, tetrachloromethane, tetrachloroethylene, chlorobenzene etc., five low density organic alcohol including 1hexanol (density, $\left.\mathrm{d}=0.819 \mathrm{~g} \mathrm{~mL}^{-1}\right), 1$-heptanol $\left(\mathrm{d}=0.820 \mathrm{~g} \mathrm{~mL}^{-1}\right), 1$-octanol $(\mathrm{d}=0.821$ $\left.\mathrm{g} \mathrm{mL}^{-1}\right)$, 1-nonanol $\left(\mathrm{d}=0.827 \mathrm{~g} \mathrm{~mL}^{-1}\right)$, and 1-decanol $\left(\mathrm{d}=0.828 \mathrm{~g} \mathrm{~mL}^{-1}\right)$ were evaluated as extractants. Among them a stable cloudy solution and good extraction recovery were observed with 1-octanol. The fine droplets of 1-octanol afford larger surface area to contact with the water sample and can be completely absorbed by MNPs after magnetic separation, so that higher extraction performance can be attained. As can be seen, 1octanol has higher extraction recovery than those obtained by other extraction solvents for the AgNPs.

\section{Effect of extraction solvent volume}

The volume of extracting solvent is an important parameter which can influence the occurrence of the cloudy state and efficiency of extraction process. To investigate the volume effect of 1-octanol, different quantities of 1-octanol (50-100 $\mu \mathrm{L})$ were used. Observably, too little 1-octanol may lead to low recoveries and the extraction efficiency was improved with the increase of 1-octanol volume. As shown in Figure 4, the recoveries for each of the AgNPs increased from 55-63\% to 86.8-109.1\% in the range of 50-80 $\mu \mathrm{L}$ of 1-octanol. The highest recovery was obtained when $80 \mu \mathrm{L}$ of 1-octanol was used for the extraction. Therefore, the volume of $80 \mu \mathrm{L}$ of 1-octanol was selected as an optimum solvent volume for further studies.

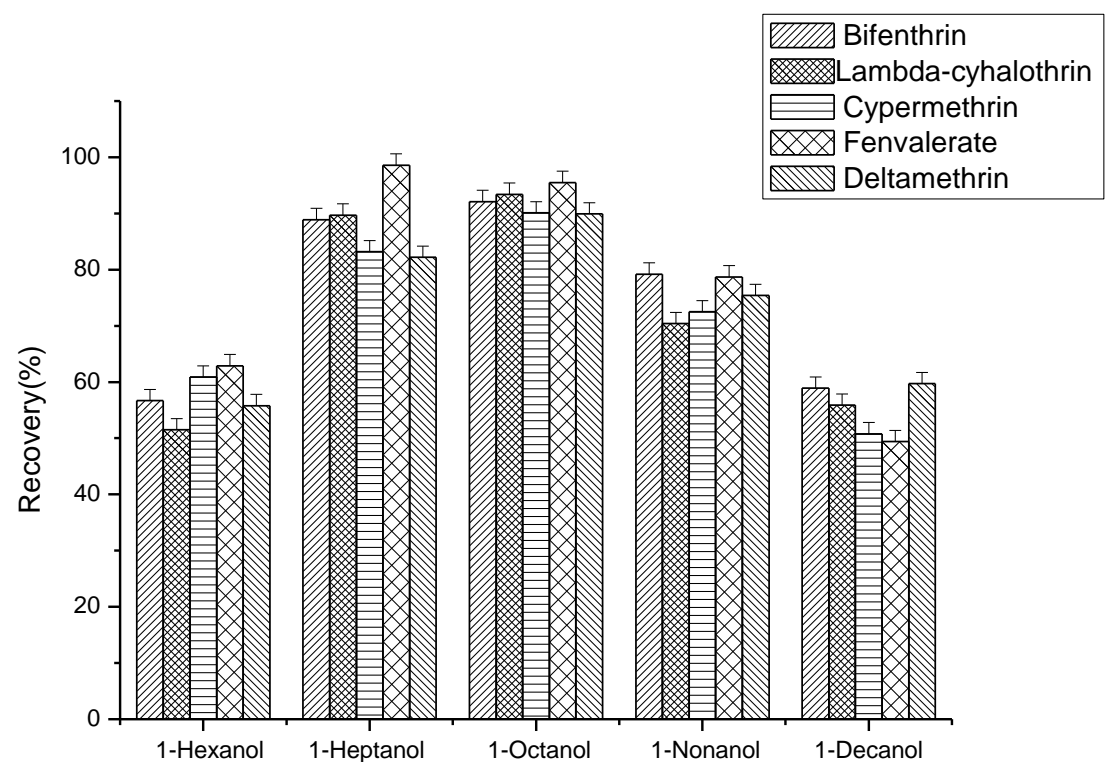

Figure 4. Selection of extraction solvent

\section{Effect of equilibration time}

In DLLME extraction, equilibration time is defined as an interval time from the occurrence of cloudy solution and before addition of magnetic adsorbents. The effect of extraction time on the adsorption was investigated from 0-120 s. The result showed that 
equilibration time has no influence on extraction efficiency. It is well-known that vortex process is an effective way to enhance mass transfer from aqueous phase to the extraction phase. Consequently, short time was required for extraction. Generally, $30 \mathrm{~s}$ of extraction time was enough to achieve high extraction recovery, and prolonged extraction time did not contribute significantly to an increase in extraction recovery. Thereby, vortex time of $30 \mathrm{~s}$ was selected.

The high viscosity of the so prepared surfactant rich phase made it necessary to dissolve the sample prior to sample introduction to FAAS. Ethanol appeared to be a feasible solvent since it readily dissolves the surfactant rich phase and it prevents degradation of the enriched nanoparticles.

\section{Evaluation of the preservation of the nanoparticle size distribution}

To gain an insight in the size distribution of the nanoparticles in real samples it is necessary to know whether the size distribution of Ag-NPs is changing during the extraction procedure or not. This was studied using TEM for imaging of the particles before and after DLLME. As shown in Figure 5, the size of particles that underwent the extraction process is more or less identical to the size before DLLME treatment. Thereby we conclude that the size distribution is not affected by the presented method. This supports the results of Yang et al. (2017) that studied CPE for metal nanoparticles. This finding is especially important because the size determination of nanoparticles is an important issue in current research. DLLME samples of Ag-NPs can therefore be used for size determination after pre-concentration.

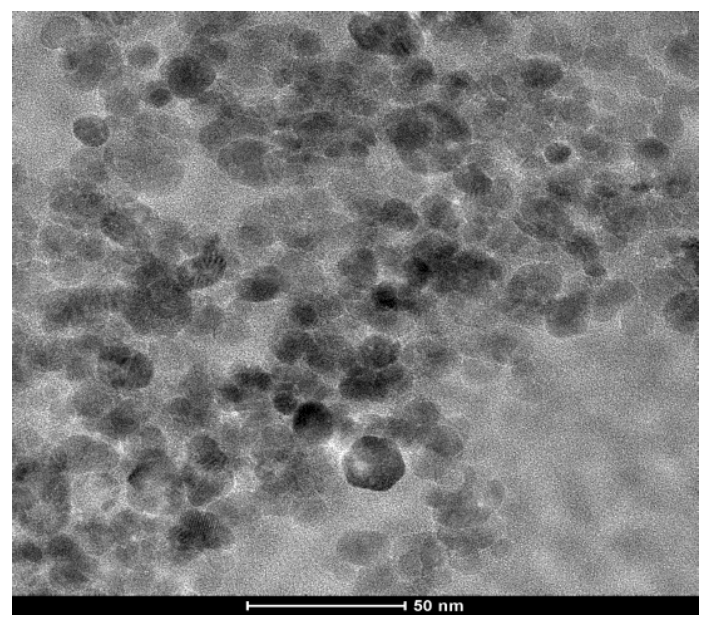

Figure 5. TEM images of synthesized AgNPs

\section{Analytical features}

The analytical characteristics of the method were evaluated under the optimum experimental conditions (Table 1). The enrichment factor (EF), relative standard deviations (RSD) and limits of detection (LOD) are effective factors to evaluate a developed analytical method. With the optimized system, the calibration graph of AgNPs was linear in the range of $10-1000 \mu \mathrm{g} / \mathrm{L}$. The calibration equation is $\mathrm{A}=7.9 \times 10^{-2} \mathrm{C}+0.003$ with a correlation coefficient of 0.9999 , where $\mathrm{A}$ is the absorbance and $\mathrm{C}$ is the $\mathrm{Ag}$ concentration in $\mu \mathrm{g} / \mathrm{L}$. The detection limits, defined as the 


$$
-5711-
$$

concentration equivalent to three times the standard deviation of the reagent blank, for AgNPs was $6.5 \mu \mathrm{g} / \mathrm{L}$. The relative standard deviation for AgNPs was $2.1 \%(\mathrm{n}=9)$. The relative recoveries of AgNPs in water samples at the spiking level of 3-20 $\mu \mathrm{g} / \mathrm{L}$ ranged from 96.7 to $108 \%$. There are many reasons, such as instrument fluctuations, operating errors, etc., so the calibration curve will appear quantitative. Recovery rates of $80 \%$ to $120 \%$ are generally considered normal. The enhancement factor, defined as the ratio of slope of preconcentrated samples to that obtained without preconcentration, was 57 for AgNPs.

Table 1. Analytical characteristics of the method

\begin{tabular}{c|c}
\hline Parameter & Analytical feature \\
\hline Linear range $(\mu \mathrm{g} / \mathrm{L})$ & $10-1000$ \\
$\mathrm{R}^{2}$ & 0.9999 \\
Limit of detection $(\mu \mathrm{g} / \mathrm{L})$ & 6.5 \\
$\mathrm{RSD}(\%)(\mathrm{n}=9)$ & 2.1 \\
Enrichment factor & 57 \\
Pre-concentration time $(\mathrm{min})$ & $<10$ \\
Recovery $(\%)$ & $96.7-108.0$ \\
\hline
\end{tabular}

\section{Effect of foreign ions}

To regard of the high sensitivity of FAAS, the interference connected with the DLLME procedure was studied. Due to cations may react with AgNPs and lead to the decrease of extraction efficiency. $10 \mathrm{~mL}$ sample solution containing $\mathrm{Ag}^{+}$and other ions were prepared and treated with the developed procedure. The tolerance limit was defined as the foreign ion concentration causing a change in the absorbance of less than $\pm 5 \%$. Table 2 shows the concentration of the interferential ions, the recovery is tolerable.

Table 2. Effects of the matrix ions on the recoveries of the examined metal ions

\begin{tabular}{c|c|c|c}
\hline \multirow{2}{*}{ Ions } & \multirow{2}{*}{ Concentration (ug/L) } & Pd & $\mathbf{A g}$ \\
\cline { 2 - 4 } & $10 \times 10^{3}$ & 105.0 & 104.1 \\
$\mathrm{Na}^{+}$ & $10 \times 10^{3}$ & 104.2 & 104.8 \\
$\mathrm{~K}^{+}$ & $10 \times 10^{3}$ & 103.5 & 102.2 \\
$\mathrm{Cl}^{-}$ & 10 & 99.1 & 101.1 \\
$\mathrm{Ca}^{2+}$ & 0.5 & 99.2 & 96.8 \\
$\mathrm{Mg}^{2+}$ & 0.5 & 100.7 & 98.8 \\
$\mathrm{Cr}^{3+}$ & 0.5 & 103.4 & 99.2 \\
$\mathrm{Mn}^{2+}$ & 0.5 & 102.2 & 100.1 \\
$\mathrm{Zn}^{2+}$ & 0.5 & 98.7 & 99.7 \\
$\mathrm{Cd}^{2+}$ & 0.5 & 99.6 & 100.8 \\
$\mathrm{Ni}^{2+}$ & 0.5 & 108.7 & 98.5 \\
$\mathrm{~Pb}^{2+}$ & 0.5 & 102.6 & 99.9 \\
$\mathrm{Cu}^{2+}$ & \multicolumn{2}{c}{} \\
\hline
\end{tabular}




$$
-5712-
$$

\section{Analysis of real samples}

To further evaluate the applicability of the proposed method, real environmental water samples were analyzed and the recoveries were determined by spiking 3-20 $\mu \mathrm{g} / \mathrm{L}$ AgNPs. The WWTP water sample was obtained from our laboratory (Bijie, China), the river water sample from LiuCang Qiao River (Bijie, China). As shown in Table 3, the obtained recoveries of AgNPs were in the range of 96.7-108\%, which was satisfactory with regard to the low spiking level. No significant difference between recoveries for samples with or without filtration was observed, suggesting that the presence of natural particles in the samples had no significant effects on the DLLME of AgNPs at concentrations $20 \mu \mathrm{g} / \mathrm{L}$. This result indicates that FAAS can be adopted to identify and quantify the AgNPs content in environmental samples.

Table 3. Determination and identification of AgNPs in environmental waters by the proposed method

\begin{tabular}{c|c|c|c}
\hline Sample & AgNPs added $(\boldsymbol{\mu g} / \mathbf{L})$ & AgNPs found $(\boldsymbol{\mu g} / \mathbf{L})$ & Recovery $(\boldsymbol{\%})$ \\
\hline \multirow{4}{*}{ River water } & 0 & $* \mathrm{ND}$ & - \\
& 5 & $4.9 \pm 0.3$ & $98.0 \pm 0.6$ \\
& 10 & $10.8 \pm 0.5$ & $108.0 \pm 5.0$ \\
& 20 & $20.5 \pm 0.6$ & $102.5 \pm 3.0$ \\
\multirow{4}{*}{ WWTP } & 0 & $* \mathrm{ND}$ & - \\
& 3 & $2.9 \pm 0.5$ & $96.7 \pm 16.7$ \\
& 15 & $8.1 \pm 0.6$ & $101.3 \pm 7.5$ \\
& $15.8 \pm 0.7$ & $105.3 \pm 4.6$ \\
\hline
\end{tabular}

\section{Comparison with other measurements}

Table 4 compares the characteristic data of the proposed method with other methods for AgNPs reported in literature. As it can be seen, the proposed method has higher RSD and lower detection time.

Table 4. The comparison of proposed measurement with other measurements

\begin{tabular}{c|c|c|c|c|c|c}
\hline Measurement & $\begin{array}{c}\text { Sample } \\
\text { volume (mL) }\end{array}$ & $\begin{array}{c}\text { Detection } \\
\text { time (min) }\end{array}$ & $\begin{array}{c}\text { RSD (\%) } \\
(\mathbf{n = 9 )}\end{array}$ & $\begin{array}{c}\text { Injection } \\
\text { volume }(\mathbf{m L})\end{array}$ & $\begin{array}{c}\text { LOD } \\
(\boldsymbol{\mu g} / \mathbf{L})\end{array}$ & Reference \\
\hline ICP-MS & 9.5 & $>10$ & 5.6 & 5 & 0.006 & Hartmann et al. (2013) \\
ET-AAS & 40 & 5 & 9.5 & 0.2 & 0.005 & Hartmann et al. (2013) \\
FAAS & 5 & $<2$ & 2.1 & 0.2 & 6.5 & This paper \\
\hline
\end{tabular}

\section{Conclusion}

In the present study, a new microextraction technique, based on dispersive liquidliquid microextraction (DLLME) was developed for determining AgNPs in environmental water samples. $\mathrm{Na}_{2} \mathrm{~S}_{2} \mathrm{O}_{3}$ was added into the extraction system as a masking reagent of $\mathrm{Ag}^{+}$to prevent its extraction into the 1-octanol rich phase. The extraction could be achieved within $2 \mathrm{~min}$ and good extraction efficiencies were obtained. Such facile separation is essential to improve the operation efficiency which avoiding time-consuming centrifugation or freezing or manual collection of extractant. 
In addition, there are many reasons, such as instrument fluctuations, operating errors, etc., so the calibration curve will appear quantitative. Recovery rates of $80 \%$ to $120 \%$ are generally considered normal. The type of sample and matrix does not affect the detection of AgNPs. This proposed method provided a simple approach for quantification of AgNPs in environmental water samples.

\section{REFERENCES}

[1] Altunay, N., Gürkan, R., Kır, U. (2015): Ultrasound assisted-cloud point extraction combined with flame atomic absorption spectrometry for selective preconcentration and determination of $\mathrm{As}(\mathrm{V})$ in selected water and beverage samples. - Analytical Methods 7(16): 6629-6639.

[2] Beltran, J., Peruga, A., Pitarch, E., López, F. J., Hernández, F. (2003): Application of solid-phase microextraction for the determination of pyrethroid residues in vegetable samples by GC-MS. - Anal. Bioanal. Chem. 376(4): 502-11.

[3] Choi, S. Y., Jeong, S., Jang, S. H., Park, J., Park, J. H., Ock, K. S., Lee, S. Y., Joo, S. W. (2012): In vitro toxicity of serum protein-adsorbed citrate-reduced gold nanoparticles in human lung adenocarcinoma cells. - J. Toxicol. In Vitro 26(2): 229-237.

[4] Ding, J., Mao, L. J., Yuan, B. F., Feng, Y. Q. (2013): A selective pretreatment method for determination of endogenous active brassinosteroids in plant tissues: double layered solid phase extraction combined with boronate affinity polymer monolith microextraction. Plant Methods 9(1): 13.

[5] El-Shahawi, M. S., Al-Saidi, H. M. (2013): Dispersive liquid-liquid microextraction for chemical speciation and determination of ultra-trace concentrations of metal ions. - Trac. Trends Anal. Chem. 44: 12-24.

[6] Fan, J. H., Li, W. T., Hung, W. I., Chen, C. P., Yeh, J. M. (2011): Cytotoxicity and differentiation effects of gold nanoparticles to human bone marrow mesenchymal stem cells. - Biomed. Eng. Appl. Basis Commun. 23(2): 141-152.

[7] Fernández-Gutiérrez, A., Martínez-Vidal, J. L., Arrebola-Liébanas, F. J., GonzalezCasado, A., Vílchez, J. L. (1998): Determination of endosulfan and some pyrethroids in waters by micro liquid-liquid extraction and GC-MS. - Fresenius' Journal of Analytical Chemistry 360(5): 568-572.

[8] Ghaedi, M., Niknam, K., Nasiri, K. S., Soylak, K. (2013): Combination of flotation and flame atomic absorption spectrometry for determination, preconcentration and separation of trace amounts of metal ions in biological samples. - Human \& Experimental Toxicology 32(5): 504-12.

[9] Ghaedi, M., Karimipour, G., Alambarkat, E., Asfaram, A., Montazerozohori, M. (2015): Solid-phase extraction of $\mathrm{Pb}^{2+}$ ion from environmental samples onto L-AC-Ag-NP by flame atomic absorption spectrometry (FAAS). - International Journal of Environmental Analytical Chemistry 95(11): 1030-1041.

[10] Gil-García, M. D., Barranco-Martínez, D., Martínez-Galera, M., Parrilla-Vázquez, P. (2006): Simple, rapid solid-phase extraction procedure for the determination of ultra-trace levels of pyrethroids in ground and sea water by liquid chromatography/electrospray ionization mass spectroscopy Rapid. - Commun. Mass Sp. 20(16): 2395-403.

[11] Habila, M., Unsal, Y. E., Alothman, Z. A., Shabaka, Z. A., Tuzen, M. (2015): Speciation of chromium in natural waters, tea, and soil with membrane filtration flame atomic absorption spectrometry. - Analytical Letters 48(14): 2258-2271.

[12] Hartmann, G., Schuster, M. (2013): Species selective preconcentration and quantification of gold nanoparticles using cloud point extraction and electrothermal atomic absorption spectrometry. - Anal. Chim. Acta. 761: 27-33. 
[13] Khaligh, A. (2015): Graphene oxide-packed micro-column solid-phase extraction combined with flame atomic absorption spectrometry for determination of lead (II) and nickel (II) in water samples. - International Journal of Environmental and Analytical Chemistry 95(1): 16-32.

[14] Lambropoulou, D. A., Albanis, T. A. (2007): Methods of sample preparation for determination of pesticide residues in food matrices by chromatography-mass spectrometry-based techniques: a review. - Anal. Bioanal. Chem. 389(6): 1663-83.

[15] Mirzaei, M., Naeini, A. K. (2013): Determinaton of trace amounts of titanium by flame atomic absorption spectrometry after cloud point extraction. - Journal of Analytical Chemistry 68(7): 595-599.

[16] Rezaee, M., Assadi, Y., Milani Hosseini, M. R., Aghaee, E., Ahmadi, F., Berijani, S. (2006): Determination of organic compounds in water using dispersive liquid-liquid microextraction. - J. Chromatogr. A. 1116(1-2): 1-9.

[17] Van, H. E., David, F., Sandra, P. (2007): Stir bar sorptive extraction for the determination of pyrethroids in water samples: A comparison between thermal desorption in a dedicated thermal desorber, in a split/splitless inlet and by liquid desorption. - J. Chromatogr. A. 1157(1-2): 1-9.

[18] Yang, X., Jia, Z., Yang, X., Li, G., Liao, X. (2017): Cloud point extraction-flame atomic absorption spectrometry for pre-concentration and determination of trace amounts of silver ions in water samples. - Saudi Journal of Biological Sciences 24(3): 589-594.

[19] Yu, C., Zhang, S., Zhang, J., Li, S., Zhou, W., Gao, H., Lu, R. (2014): An in situ ionic liquid dispersive liquid-liquid microextraction method for the detection of pyrethroids by LC-UV in environmental water samples. - J. Brazil. Chem. Soc. 24(6): 1034-104000. 